\title{
Interruption of scheduled, automatic feeding and reduction of excess energy intake in toddlers
}

This article was published in the following Dove Press journal:

International Journal of General Medicine

30 January 2013

Number of times this article has been viewed

\section{Mario Ciampolini' \\ J Thomas Brenna ${ }^{2}$ \\ Valerio Giannellini ${ }^{3}$ \\ Stefania Bini'}

'Preventive Gastroenterology Unit, Department of Paediatrics, Università di Firenze, Florence, Italy; ${ }^{2}$ Division of Nutritional Sciences, Cornell University, Ithaca, NY, USA; ${ }^{3}$ Department of Pharmaceutical Sciences, Università di Firenze, Florence, Italy

Video abstract

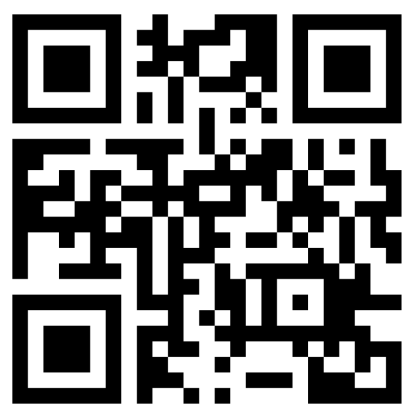

Point your SmartPhone at the code above. If you have a QR code reader the video abstract will appear. Or use: http://dvpr.es/ZuZXOb

Correspondence: Mario Ciampolini ONLUS Nutrizione e Prevenzione, Via Vigna Nuova 8, Firenze,

50132 Florence, Italy

Tel +39055 215744

Email mlciampolini@fastwebnet.it
Background: Childhood obesity due to the consumption of excess calories is a severe problem in developed countries. In a previous investigation on toddlers, hospital laboratory measurements showed an association of food-demand behavior with constant lower blood glucose before meals than for scheduled meals. We hypothesize that maternal scheduling of meals for toddlers results in excess energy intake compared to feeding only on demand (previously "on request").

Objective: We tested the cross-sectional null hypothesis of no difference in energy intake between scheduled (automatic) and demanded meals (administered after evaluation) in 24 mother-toddler (21 months old at entry) pairs with chronic, nonspecific diarrhea presenting at a clinic. We tested the same hypothesis in a subset of 14 toddlers by measuring the resting (sleeping) metabolic rate 4 hours after lunch, as well as the total daily energy expenditure (TEE) in 10 toddlers.

Methods: We trained mothers to recognize meal demands (as in the previous investigation) and to provide food in response, but required no blood glucose measurements before meals. Energy intake was assessed by a 10-day food diary, resting metabolic rate (RMR) by respiratory analyses (indirect calorimetry) in 14 toddlers, and TEE by doubly labeled water in 10 toddlers. Their blood parameters, anthropometry, and number of days with diarrhea were assessed before training and 50 days after training.

Results: RMR decreased from $58.6 \pm 7.8$ to $49.0 \pm 9.1 \mathrm{kcal} / \mathrm{kg} / \mathrm{d}(P<0.001)$ and TEE decreased from $80.1 \pm 6.9$ to $67.8 \pm 10.0 \mathrm{kcal} / \mathrm{kg} / \mathrm{d}(P<0.001)$. Energy intake decreased from $85.7 \pm 15.3$ to $70.3 \pm 15.8 \mathrm{kcal} / \mathrm{kg} / \mathrm{d}(P<0.001)$. The height $\mathrm{Z}$-score increased significantly, while weight growth was normal. Toddlers entering the study over the median RMR decreased their RMR significantly more than those below the median RMR $(P<0.01)$.

Conclusion: Scheduled meal suspension induces meal demand frequency to increase. Demanded meals are associated with significantly lower energy intake, RMR, and TEE than scheduled meals. Feeding on demand may be an effective skill in a strategy for reducing excess energy intake in the long term and in regulating body weight in toddlers and children.

Keywords: hunger, intake, meals, energy, homeostasis, blood glucose, meal pattern, intake habit, overweight, balance, chronic diarrhea

\section{Introduction}

The general obesity epidemic in food-rich countries has expanded to dangerous proportions. Childhood obesity has risen dramatically as well, accompanied by expected sequelae such as diabetes and other complications. The main contributor to obesity is excess energy intake due to excessive consumption of high-energy foods, frequent snacking, and other factors. Despite intense focus on the problem, nonsurgical 
and nonmedical methods for reducing daily energy intake compatible with normal daily life have been ineffective in the long term. ${ }^{1}$

Feeding patterns in early life establish lasting physiological changes such as increases in pancreatic beta cell numbers and adipocyte numbers that support the continuation of specific practices. ${ }^{1-7}$ Practices after weaning establish meal patterns that persist into childhood and influence subsequent nutrition and health. ${ }^{6}$ Two contrasting practices in meal initiation are scheduled feeding, in which the toddler is fed at predefined intervals (eg, 2 to 4 hours), and on-demand feeding initiated by the toddler's request. ${ }^{7}$ Scheduled feeding is defined as the initiation of meals when based on time of day or external events, whereas meals in on-demand feeding are initiated only upon the request of the toddler for food. The two feeding types influenced the energy intake and dynamic balance of fasting and postprandial macronutrients in blood ${ }^{8}$ in a recent investigation on toddlers similar to the one presented here. ${ }^{7}$ The intake habits of the selected subjects were representative of the Tuscan healthy infant population. ${ }^{7}$ After adequate training with blood glucose (BG) measurements at hunger arousal, adults and mothers were able to estimate current BG with high accuracy. ${ }^{7-9}$ At meal onset, mean energy intake was $1148 \pm 314 \mathrm{kcal} /$ day and the mean BG was $86.9 \pm 9.4 \mathrm{mg} /$ dL during a week of scheduled feeding and $946 \pm 230 \mathrm{kcal} /$ day intake and $76.4 \pm 6.7 \mathrm{mg} / \mathrm{dL}$ mean BG in toddlers of trained mothers during demanded feeding. ${ }^{7}$ Scheduled feeding was associated with significantly increased functional complaints such as intestinal discomfort and diarrhea ${ }^{7}$ in the same recent investigation. Similarly, scheduled feeding was also associated with insulin resistance, body weight increases, and functional bowel disorders in adults. ${ }^{10,11}$ Scheduled feeding may induce excess caloric consumption by requiring the toddler to eat before the exhaustion of energy consumed in the previous meal. ${ }^{8}$ The habitual repetition of eating prior to the return of BG to fasting levels produces insulin resistance, excess weight, and risks associated with subclinical inflammation.

Implementing demand-feeding in toddlers by training caregivers to recognize hunger and food demand is relatively easy, simply requiring the suspension of scheduled food administration and learning the habit of regular attention near expected mealtimes. This pattern is referred to as the initial hunger meal pattern (IHMP), or recognizing hunger. ${ }^{11}$ The habit is easily learned by caregivers, and indeed is maintained spontaneously in 20\%-30\% of untrained control toddlers and adults that show a mean weekly BG and insulin sensitivity associated with hunger recognition similar to subjects after training. ${ }^{7,11}$ IHMP is a tool for breaking the habit of automatic feeding, implementing habitual evaluation before meals in order to maintain null energy balance meal by meal for years, to suppress fattening, to decrease immune intestinal stimulation, to decrease body weight in overweight adults, to maintain body weight in normal-weight infants and adults, and to increase body weight in malnourished infants. ${ }^{7-15}$

Intake and mean BG data were generated based on home diary records, which are subject to biases in research participants instructed to alter their dietary habits. To test our previous reports with objective measures, we devised the present study to investigate with indirect and doubly labeled water-based calorimetry the influence of our demand-feeding training on toddlers. Food diary reports showing decreased energy intake in the absence of undesirable body weight loss in normal-weight participants were collected similarly to our previous protocols and compared with calorimetry to more objectively evaluate energy metabolism. Our reported reduction in energy intake without undesirable reduction of body weight is expected to reduce total energy expenditure via reductions in the resting metabolic rate (RMR).

\section{Methods Study design}

Thirty children who presented from 1992 to 1999 with chronic or intermittent diarrhea (functional disorder of bowel, irritable bowel syndrome [IBS], in infancy chronic non-specific diarrhea) were recruited, examined, treated, and reexamined after 50 days, similar to a protocol reported previously. ${ }^{7}$ Diarrhea was defined as the daily emission of more than 5 grams of feces per $\mathrm{kg}$ of body weight under a usual Western diet - ie, with $0.6 \pm 0.4 \mathrm{~g}$ of fiber $/ \mathrm{d} / \mathrm{kg}$. ${ }^{16}$ Children with histories of either chronic (minimum of 2 months) or intermittent diarrhea (ill with diarrhea for at least 15 of the preceding 90 days) were enrolled. The clinical assessment of all patients consisted of a routine physical examination and diagnostic biochemical and microbiological evaluations to rule out disorders such as lower respiratory tract infections, urinary tract infections, lactose intolerance, cystic fibrosis, inflammatory bowel disease, hepatitis, pancreatitis, and bacterial and parasitic infections. ${ }^{7,12-15}$ The intervention consisted of the provision of diets high in fruits and vegetables, and energy intake was adjusted meal by meal to regulate the emergence of food demand before planned mealtimes (IHMP). ${ }^{72-15}$ Mothers adjusted energy administration meal by meal via this post hoc biofeedback. Clinical progress was assessed primarily from reports of the mean number of days with diarrhea and 
other symptoms, the number of outdoor and sleeping hours per day, and by blood examination.

Approval from institutional reviews for human use was obtained from the Ospedale A Meyer, Firenze, Italy and Cornell University, Ithaca, NY, USA. Informed consent was obtained from all of the subjects' guardians.

\section{Participants}

The participants were healthy as judged from C-reactive protein (CRP) and an absence of intestinal or other organ diseases, except for diarrhea relapses. ${ }^{7}$ Total daily energy expenditure (TEE) was determined in a subset of participants (TEE subset): 12 children, 10-40 months of age, were recruited, with ten children completing the protocol; the others were unwilling or unable to complete the protocol. RMR was determined in another subset of participants (RMR subset): 18 children of the same age were recruited and 14 completed the protocol, which was conducted in the afternoons after examinations. Two failed repeatedly to sleep at the postexamination, and two had difficulty returning for the final examination due to time and money. The two subsets were equivalent by age, weight, diagnosis, and treatment and are presented together, except for metabolic measurements.

\section{Clinical assessments}

Clinical assessments were performed for diagnostic purposes, to assess compliance with the study protocol, to measure food intake, and to evaluate the effects of the training. Adherence to the dietary regimen and physical activity patterns were monitored throughout the observation period by interviewing the principal caretakers by phone (every day initially), during clinical visits during follow-up, from the clinical evaluations of the children, and from the diary reports. Clinical assessments included: CRP levels; standard hematological evaluations; urinalysis; urine cultures; the examination of stools for occult blood, ova and parasites, and Helicobacter pylori antibodies; and bacterial cultures for potential pathogens. Comprehensive biochemical profiles were obtained on all children. Measurements included levels of serum albumin, hemoglobin, iron, transferrin, calcium, phosphorous, copper, Zinc, total and HDL cholesterol, triglycerides, alkaline phosphatase, alanine aminotransferase, aspartate aminotransferase, total immunoglobulin, IgA, IgM, IgG, antigliadin antibodies, anti-transglutaminase, and ferritin. Plasma folate, B12, and IgE were also determined, as were red blood cell volume and platelet and eosinophil counts. ${ }^{12,13}$ Anthropometric measurements were obtained by standard techniques as described previously. ${ }^{7,12,13}$ Mean ( \pm SD) age, weight, length or height, triceps and quadriceps skinfold thicknesses, and corresponding anthropometric National Center for Health Statistics scores at recruitment and at the 50-day follow-up are summarized in Table 1.

TEE, dietary intake, total body water, body weight, height or length, and triceps and quadriceps skinfold thickness were measured at recruitment and 50 days after the initiation of the therapeutic dietary regimen in 10 children (TEE subset). RMR recorded during post-lunch afternoon naps and all other measurements listed above except for TEE were measured in 14 children (RMR subset). In this chronological order, we performed TEE and RMR investigations in the same clinical type of subjects and in the same setting (Florence University). However, the presentation first discusses the RMR study, followed by the TEE study.

\section{IHMP}

We asked mothers to suspend food intake for a few hours, and to make note of the specific manifestations of their child's first food demand. ${ }^{7}$ Crying; mood changes, such as loss of enthusiasm for playing; gestural or verbal demands; and searching for food without any external stimulus all were considered to be signs of demand (initial demand [ID] or initial hunger [IH]). Mothers learned to discern ID manifestations. The principal investigator called every caregiver at the end of the first training day to ascertain the actual change(s) made by the mother. The first adherence to this protocol resulted in a mean meal consumption after a delay of 2 hours ( 0 - to 48 -hour range). At subsequent mealtimes, mothers evaluated arousals according to their first experience to assess if the demands were due to hunger. Our previous studies ${ }^{7-15}$ show that BG is significantly lower after training in children that demand food than in those who do not, and we previously reported the validation of demand recognition..$^{7-9}$ After

Table I Group composition and the effects of training to recognize food demand on anthropometry in 24 toddlers ( 9 females, 15 males)

\begin{tabular}{lll}
\hline & At recruitment & After $\mathbf{5 0}$ days \\
\hline Age (months) & $21.0 \pm 7.3$ & $22.7 \pm 7.5$ \\
Weight $(\mathrm{kg})$ & $11.1 \pm 2.4$ & $11.4 \pm 2.3^{* *}$ \\
Length $(\mathrm{cm})$ & $83.4 \pm 8.1$ & $85.3 \pm 8.0^{* * *}$ \\
Weight/length (\%) & $95.0 \pm 8.8$ & $93.6 \pm 8.4^{* * *}$ \\
Weight Z-score (SD) & $-0.5 \pm 1.2$ & $-0.6 \pm 1.2$ \\
Height Z-score (SD) & $-0.7 \pm 1.1$ & $-0.5 \pm 1.1^{* * *}$ \\
Arm skinfold thickness (mm) & $7.2 \pm 1.6$ & $6.8 \pm 8.2$ \\
Leg skinfold thickness $(\mathrm{mm})$ & $11.3 \pm 2.9$ & $11.0 \pm 2.6$ \\
\hline
\end{tabular}

Notes: Values are expressed as means \pm standared deviation (SD). Asterisks indicate a significant difference (Student's $t$-test on paired samples: $* * P<0.01$; $* * * P<0.001$ ). 
training, with 42 measurements at hunger arousal, we investigated, in the hospital laboratory before breakfast, 16 toddlers not demanding food in comparison with 54 who were demanding food. ${ }^{7}$ No demand was associated with a significantly higher mean BG than the condition of food demand $(96.3 \pm 10.5 \mathrm{mg} / \mathrm{dL}$ versus $74.6 \pm 7.7 \mathrm{mg} / \mathrm{dL}$; $P=0.0001)$. Based on these studies, ID was conceived as a threshold phenomenon triggered by low energy availability in blood, indicated by low $\mathrm{BG},{ }^{7-9}$ normal activity is not inhibited by low energy. The intervention may be conceived as an abrupt weaning of the mother and child off the automatic, scheduled feeding for implementing an habitual evaluation on the amount to be eaten $(150 \mathrm{kcal}$ for infants and 300 for adults initially). The interaction between subject (mother) and expert was necessary to wean off the automatic meal onsets and to stop any dependence on fullness sensations (manifestations) toward meal end. The fullness sensations (manifestations) tended to deceive toward excessive intake and long inter-meal intervals. Mothers received information on food energy contents, balance factors, and recommended vegetable intake and physical activity level per day. The recommended fruit and vegetable amount was $0.5 \mathrm{~kg} / \mathrm{day}$. The investigators discussed and promoted energy expenditure by decreases in overheating and overclothing and by fostering outdoor and gym activities. The absence of IH manifestations before meals was treated in subsequent meals by alternations in behavior that would enhance hunger, such as a decrease in energy-dense food in subsequent meals. Avoiding snacks was suggested, though earlier-than-optimal IH was satisfied with fruit and adequate energy-dense food if needed. Social obligations like parties and school catering were included in planning the intake amount and timing of the previous and subsequent meals.

\section{Diary compilation}

Written food intake records were collected for 10 consecutive days before any intervention to assess dietary compliance and to estimate energy and fiber intake. Also recorded were the times spent at play and asleep, as well as daily stool weights. Caregivers were contacted by telephone at least seven times between the two evaluations to assess their child's feeding behavior and general activity levels.

Food intake was estimated by weighing or measuring food volumes before and after cooking. Measurement utensils were provided to the caretakers by the investigators, and all leftovers and portions served to the child after cooking were weighed or measured. All data were recorded on special forms supplied by the investigators, checked by a dietician at their return, and reported on a computer program. Energy intake was calculated according to the formula put forth by McCance et al. ${ }^{17}$ Energy from unavailable carbohydrates was added to the energy content of the food in the proportion of $2 \mathrm{kcal} / \mathrm{g}$ of fiber intake. ${ }^{18,19}$ Each caretaker was instructed in food measurement and weighing by a dietician during the child's hospitalization. Particular care was suggested for oil added to vegetables. Intake measurements were obtained at the time that samples were collected for estimating TEE or surrounding the period that the RMR measurements were obtained.

Preweighed disposable diapers were used to assess stool weights. Urine bags were used to prevent the contamination of feces with urine. Diapers were checked every 2 hours during the daytime and all weights were recorded in the diary kept by the caregivers. Diarrheic feces were not used for the measurement of energy elimination by feces.

\section{Measurement of RMR during afternoon naps}

RMRs were measured during sleep between $3 \mathrm{pm}$ and $4 \mathrm{pm}$ following a 3.5 - to 5-hour fast during the 10-day home diary compilation, 30 minutes or more after the children had fallen asleep, for at least 30 minutes. Metabolic rates by indirect calorimetry were measured by a Deltatrac II metabolic monitor (Datex-Ohmeda, Madison, WI, USA).

\section{Administration of labeled water and collection of urine samples}

Labeled water was diluted in a drink known to be accepted by each child and was administered in the laboratory to all subjects after an overnight fast. Care was taken to avoid spills and to assure the completeness of ingestion. All containers were washed three times with the drink and the subjects consumed each of the washings.

Recruitment urine samples were collected from each child before the oral administration of ${ }^{2} \mathrm{H}_{2}{ }^{18} \mathrm{O}(1.5 \mathrm{~g} / \mathrm{kg}$ ${ }^{18} \mathrm{O}$ and $0.22 \mathrm{~g} / \mathrm{kg}{ }^{2} \mathrm{H}_{2} \mathrm{O}$ ). Initial post-dose urine samples were collected in the laboratory no sooner than 2 hours after the administration of the dose. All subsequent urine samples were collected at home. The second post-dose sample was collected approximately 4 hours post-dose. Subsequent samples were collected on alternate days thereafter for 10 days. All caregivers were carefully instructed in collection procedures to avoid contamination and evaporation. Urine samples were stored at $-20^{\circ} \mathrm{C}$ until analysis. 


\section{Isotope ratio measurements}

For deuterium analysis, $2 \mu \mathrm{L}$ aliquots of urine were vacuum-distilled into quartz tubes containing zinc (Biogeochemical Laboratories, Bloomington, IN, USA). The water was frozen and the tubes evacuated to $<10^{-4} \mathrm{mbar}$ and then flame-sealed. Water collected by vacuum distillation was reduced to hydrogen gas by heating at $450^{\circ} \mathrm{C}$ for 1 hour. The $\mathrm{H} /{ }^{2} \mathrm{H}$ ratio was measured via dual inlet analysis on a ThermoFinnigan (Bremen, Germany) MAT 252 isotope ratio mass spectrometer operated at a $10 \mathrm{kV}$ accelerating voltage.

The urine was prepared for ${ }^{18} \mathrm{O} /{ }^{16} \mathrm{O}$ by equilibrating $1 \mathrm{~mL}$ of urine with $1.5 \mathrm{~mL} \mathrm{STP} \mathrm{CO}_{2}$ at $35^{\circ} \mathrm{C} \pm 0.10^{\circ} \mathrm{C}$ for 24 hours in Vacutainer (BD, Franklin Lakes, NJ, USA) tubes $(100 \times 16 \mathrm{~mm})$. The $\mathrm{CO}_{2}$ was analyzed using a continuous flow system employing a HaySep D molecular sieve (Alltech/ Grace, Deerfield, IL, USA) maintained at $150^{\circ} \mathrm{C}$ for $\mathrm{CO}_{2}$ purification. Isotope ratios were also determined on a Finnigan MAT 252 isotope ratio mass spectrometer operated at an $8 \mathrm{kV}$ accelerating voltage. The results of both oxygen and hydrogen isotope measurements were expressed in delta $(\delta)$ permil (\%o) units against Vienna-standard mean ocea $\mathrm{n}$ water. ${ }^{20}$

\section{Estimation of energy expenditure and dilution spaces}

A multipoint linear regression fit to a plot of the natural logarithm of the atom fraction over recruitment versus time was used to fit a mono-exponential natural logarithm decay of ${ }^{18} \mathrm{O}$ and ${ }^{2} \mathrm{H}$ enrichments in the urine samples. The fractional turnover rates of ${ }^{18} \mathrm{O}\left(\mathrm{R}_{\mathrm{o}}\right)$ and ${ }^{2} \mathrm{H}\left(\mathrm{R}_{\mathrm{d}}\right)$ were assumed to be equal to the slope of the corresponding decay curve. Dilution spaces were calculated as:

$$
\mathrm{N}_{\mathrm{o}} \text { or } \mathrm{N}_{\mathrm{d}}, \mathrm{mol}=(\mathrm{d} / \mathrm{MW})(\mathrm{APE} / 100)\left(1 / \mathrm{R}_{\mathrm{std}}\right) \text {, }
$$

where $\mathrm{d}$ is the amount of ${ }^{2} \mathrm{H}_{2} \mathrm{O}(\mathrm{g})$ - or ${ }^{18} \mathrm{O}$-labeled water, MW is the molecular weight of the water $(\mathrm{g} / \mathrm{mol}), \mathrm{APE}$ is the atom percent excess of the isotope in the labeled water, $\mathrm{d}$ is the intercept or zero-time enrichment of ${ }^{18} \mathrm{O}$ or ${ }^{2} \mathrm{H}$ over recruitment derived from the linear regression analyses of the isotope decay rates, and $R_{\text {std }}$ is the ${ }^{18} \mathrm{O} /{ }^{16} \mathrm{O}$ or ${ }^{2} \mathrm{H} /{ }^{1} \mathrm{H}$ ratio of Vienna-standard mean ocean water, which has values of 0.0020052 and 0.00015576 , respectively.

$\mathrm{CO}_{2}$ production rates were calculated using the equation $^{21}$

$$
\mathrm{rCO}_{2}=(\mathrm{N} / 2.08)\left(1.01 \mathrm{k}_{\mathrm{o}}-1.04 \mathrm{k}_{\mathrm{H}}\right)-0.246 \mathrm{r}_{\mathrm{Gf}}
$$

with

$$
\mathrm{N}=1.01 \mathrm{~N}_{\mathrm{O}} \text { and } \mathrm{r}_{\mathrm{Gf}}=1.05 \mathrm{~N}\left(\mathrm{k}_{\mathrm{o}}-\mathrm{k}_{\mathrm{H}}\right),
$$

where $\mathrm{N}$ is the total body water dilution space $(\mathrm{mol}) ; \mathrm{k}_{\mathrm{o}}$ and $\mathrm{k}_{\mathrm{H}}$ are the $\mathrm{O}$ and $\mathrm{H}$ washout rates, respectively; and $\mathrm{r}_{\mathrm{Gf}}$ is the rate of water loss by gaseous fraction routes.

\section{Isotopes}

Deuterium oxide (99.8 atomic ratio) was obtained from Aldrich Chimica (Milano, Italy). Water labeled with oxygen-18 (10 atomic ratio) was obtained from Enritech Enrichment Techno, Ltd. (Weizman Campus, Rehovot, Israel). Water was ultrafiltered prior to administration.

\section{Statistical analysis}

Data are presented as mean \pm SD. The statistical significance of the mean changes in terms of the values of interest (eg, energy expenditure) between pre- and post-dietary interventions was calculated using a paired $t$-test at a $95 \%$ confidence level. The study size was conceived as the size necessary to obtain significant differences in energy intake.

\section{Results and discussion}

By adjusting meal sizes and the composition or timing of food intake, $94.5 \% \pm 16.4 \%$ of meals were preceded by ID as assessed by diary reports after training. All subjects together significantly decreased their mean energy intake and increased their fruit and vegetable intake (Table 2). We assumed that the RMR and TEE groups were identical. Age, anthropometry measures, and clinical assessments coincided. Energy intake decreased from $86.0 \pm 17.3 \mathrm{kcal} /$ $\mathrm{kg} / \mathrm{d}$ to $70.7 \pm 18.8$ and from $87.8 \pm 13.9$ to $71.1 \pm 14.6$ in the two groups and showed no difference at recruitment from the local population of the same age. ${ }^{7}$ Afternoon RMR (sleeping MR) fell by $-9.6 \pm 8.6 \mathrm{kcal} / \mathrm{kg} / \mathrm{d}(-15.4 \%$ of the value at recruitment), ie, from $58.6 \pm 7.8$ to $49.0 \pm 9.1 \mathrm{kcal} / \mathrm{kg} / \mathrm{d}$ (Table 2). Daily energy expenditure fell by $-12.3 \pm 7.2 \mathrm{kcal} / \mathrm{kg} / \mathrm{d}(-15.5 \%)$, ie, from $80.1 \pm 6.9 \mathrm{kcal} /$ $\mathrm{kg} / \mathrm{d}$ at recruitment to $67.8 \pm 10.0 \mathrm{kcal} / \mathrm{kg} / \mathrm{d}$ at follow-up (Table 2). The physical activity level was 1.4 at recruitment and remained at 1.4, as reported in normal infants of this age. ${ }^{22}$ Even with no change in physical activity level, diaries reported a significant increase in outdoor living after training (Table 2), suggesting no decrease in physical activity after training. The decrease in RMR $(-9.6 \pm 8.6 \mathrm{kcal} / \mathrm{kg} / \mathrm{d})$ showed no difference from the decrease in TEE $(-12.3 \pm 7.2 \mathrm{kcal} / \mathrm{kg} / \mathrm{d})$. These decreases objectively reject equivalence between scheduled and demanded meals (null hypothesis). 
Table 2 Effects of training on food intake, energy expenditure, and fecal emission

\begin{tabular}{llll}
\hline & Recruitment & After $\mathbf{5 0}$ days & Decrease \\
\hline RMR $(\mathrm{kcal} / \mathrm{kg} / \mathrm{d})$ & $58.6 \pm 7.8$ & $49.0 \pm 9.1^{* * *}$ & $-9.6 \pm 8.6(+15.4 \%)$ \\
TEE $(\mathrm{kcal} / \mathrm{d} / \mathrm{kg})$ & $80.1 \pm 6.9$ & $67.8 \pm 10.0^{* * *}$ & $-12.3 \pm 7.2(+15.5 \%)$ \\
Energy intake $^{\mathrm{a}}$ & $85.7 \pm 15.3^{\mathrm{b}}$ & $70.3 \pm 15.8^{* * *, c}$ & $-15.3 \pm 17.0(-17.9 \%)^{\mathrm{d}}$ \\
PALe & 1.366 & 1.384 & \\
Meals per dayf & $4.40 \pm 0.60$ & $4.15 \pm 0.53^{* *}$ & $(-5.7 \%)$ \\
Vegetable intake $(\mathrm{g} / \mathrm{d})$ & $54 \pm 53$ & $290 \pm 85^{* * *}$ & \\
Fruit intake $(\mathrm{g} / \mathrm{d})$ & $114 \pm 89$ & $175 \pm 121^{*}$ & $3.2 \pm 1.7^{* *}$ \\
Outdoor hours & $1.9 \pm 1.4$ & $88.2 \pm 36.4^{* *}$ & $78 \pm 32$ \\
Fecal weight $(\mathrm{g} / \mathrm{d})$ & $62.3 \pm 26.7$ & \\
Fecal energy $(\mathrm{kcal} / \mathrm{d})$ & $94 \pm 40$ & & \\
\hline
\end{tabular}

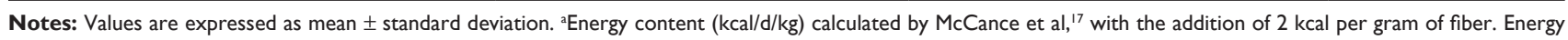
intake per $\mathrm{kg}$ versus total daily expenditure per $\mathrm{kg}$ bat recruitment $(P=0.39)$, cafter training $(P=0.28)$, and ${ }^{\mathrm{d}}$ on pre/post decreases $(P=0.90)$; ${ }^{\mathrm{e}} P \mathrm{~L} L$ (physical activity level) is the proportion between the total daily energy expenditure (TEE) in a group and the resting metabolic rate (RMR) in the other. The normal level is I.4 within the same group at this age; 22 the meal comprised a higher intake than $20 \mathrm{kcal}$. Asterisks indicate that the pre/post difference is significant $($ Student's $t$-test: $* P<0.05$; $* * P<0.01$; $* * * P<0.001)$.

Instructions for the first training day interrupted automatic, habitual food administration at mealtimes and implemented habitual evaluation of either the arousal or lack thereof of the child's hunger manifestations. A habit change may produce powerful effects. ${ }^{23}$ Social and physical activity levels and healthy growth were maintained and even improved with fruit- and vegetable-rich meals providing modest calories that maintained toddlers in inter-meal intervals until demand. In overweight adults, both high vegetable intake and IH meal onset contributed to decreasing energy intake in comparison with scheduled meals. ${ }^{10}$ Further, these more detailed studies support our findings over many years that mothers can easily maintain usual mealtimes by adjusting meal content to satiate their toddlers for expected activity in the desired interval between meals. ${ }^{12-15}$ ID arises spontaneously as a habit in $20 \%$ of untrained toddler-mother pairs, but can be easily learned with coaching. ${ }^{7-11}$ For infants and toddlers, the pattern relies on the evaluation of food demand prior to each mealtime, validated in a previous study by BG measurements. ${ }^{7}$ At the end of the investigation in the laboratory, mothers stated whether their infant was hungry or not hungry, and estimated BG shortly before blood sampling and before breakfast. The 54 hungry infants of the trained group had a significantly lower BG $(74.6 \pm 7.7 \mathrm{mg} / \mathrm{dL})$ compared to the 16 not-hungry infants $(96.3 \pm 10.5 \mathrm{mg} / \mathrm{dL} ; P=0.001)$. Moreover, the trained mothers of hungry infants were able to estimate BGs $(77.4 \pm 3.6 \mathrm{mg} / \mathrm{dL}$; estimation error: $5.8 \% \pm 4.5 \%$ of the measured $\mathrm{BG}$ ) more accurately than the mothers of not-hungry infants (estimated BG: $88.7 \pm 5.9 \mathrm{mg} / \mathrm{dL}$; estimation error: $10.9 \% \pm 7.5 \% ; P=0.0001$ ). The meaning of this validation is that mothers can recognize food requests as manifestations that arise at a constant (low) BG in their infants, ie, corresponding to a physiologically identifiable condition. ${ }^{7}$
Our previous data from diaries show that infants under the age of two self-regulate and that mothers correctly recognize their child's manifestations of hunger. Our present biophysically objective data show that toddlers can spontaneously regulate and significantly reduce their intake by food administration at the time of their hunger manifestations (Table 2). ${ }^{7}$ Internal cues have been generally suggested to address eating patterns in overweight adults, although this intervention is ineffective considering the current obesity epidemic. ${ }^{1}$ Adults' meals at mealtimes are powerfully established by habits. ${ }^{23}$ Adults first require meal suspension to interrupt the habitual pattern in the first training day, and then learn and show the identification of IH by pre-meal BG checking. Taken together, our results indicate that, after two years of age, eating patterns based on offered food become powerfully established. ${ }^{23}$ Mothers easily acquire the habit of evaluating food demand prior to each mealtime instead of automatically offering food. Thus, BG checking by adults is necessary to learning self-regulation ${ }^{7-11}$ and unnecessary below two years of age (Table 2).

Both weight and length increased significantly over the 50-day intervention (Table 1). Weight for length significantly decreased, which was attributable to the increase in length on the basis of Z-scores, with no change in weight Z-scores

Table 3 Effects of training on toddlers' symptoms

\begin{tabular}{lcl}
\hline & Recruitment & After $\mathbf{5 0}$ days \\
\hline Diarrhea & $21.1 \pm 12.8^{\mathrm{a}}$ & $1.5 \pm 1.8^{* * * *}$ \\
Vomiting & $0.8 \pm 1.4^{\mathrm{a}}$ & $0.4 \pm 0.9$ \\
Fever & $3.4 \pm 6.1^{\mathrm{b}}$ & $0.6 \pm 1.0^{*}$ \\
Drug intake & $15.2 \pm 15.0^{\mathrm{b}}$ & $0.8 \pm 3.2^{* * *}$ \\
\hline
\end{tabular}

Notes: ${ }^{2}$ Number of days with the symptoms within the 50 days of the study; ${ }^{b}$ number of days with fever or drug administration within the preceding 30 days. Asterisks indicate that the pre/post differences are significant (Student's $t$-test: $* P<0.05 ; * * * P<0.001)$ 
Table 4 Effects of training on a few blood parameters

\begin{tabular}{lll}
\hline & Recruitment & After 50 days \\
\hline Triglycerides $(\mathrm{mg} / \mathrm{dL})$ & $83.2 \pm 35.8$ & $64.4 \pm 18.8^{* *}$ \\
Transferrin saturation $(\%)$ & $23.9 \pm 14.7$ & $35.8 \pm 13.8^{*}$ \\
Plasma folate $(\mathrm{ng} / \mathrm{mL})$ & $10.4 \pm 5.5$ & $16.4 \pm 4.5^{* * *}$ \\
\hline
\end{tabular}

Note: Asterisks indicate that the pre/post differences are significant (Student's $t$-test: $* P<0.05 ; * * P<0.01$; ***P $<0.001$ ).

(Table 1). Weight-for-age showed no change (not presented). The arm and leg skinfold thicknesses showed no significant changes.

No side effects, such as fainting or sleepiness, were observed from the training. The mean number of days with diarrheal symptoms dropped from $21.1 \pm 12.8$ days of the 50 days preceding the initiation of treatment to $1.5 \pm 1.8$ (days $/ 50 \mathrm{~d} ; P<0.001$ ) during the interval between the start of the therapeutic dietary regimen and the final follow-up evaluation. In association, days with fever and the use of antibiotics and antipyretics significantly decreased (Table 3 ). The investigators, through daily interaction with participants, noted that both mothers and toddlers maintained good moods, physical and mental effectiveness, and freedom to choose food, except for a shift toward fruits and vegetables. The trained group significantly increased their serum folate and transferrin saturation and decreased their plasma triglycerides (Table 4).

We excluded a control group to avoid interventions on infants without treatment or diagnostic purposes. This exclusion and the low number of investigated subjects prevented us from publishing the present findings on IHMP as a lasting method to stop the worldwide epidemic of fattening, insulin resistance, and the associated immune derangement and vascular risks. The number of investigated infants is also disproportionately low compared to the investigations by diary of mean BG and daily energy intake that we published in the meantime. IHMP reduced energy intake and mean BG in controlled studies on 88 infants after 7 months; ${ }^{12,13}$ 114 infants after 4 years $;{ }^{14}$ on $311,244,125$, and 88 infants during a sequential follow-up with assessments after 5 months and 4, 8, and 12 years, respectively (see Table 1 in Ciampolini et al ${ }^{15}$ ); on 143 infants after 4 months; ${ }^{7}$ and in 107 normal-weight adults and 74 overweight adults after five months. ${ }^{10}$ In adults, the decrease in energy intake and mean BG was associated with decreases in insulin resistance and body weight, except for adults who were normal-weight and insulin-sensitive. ${ }^{10,11}$ Moreover, even though the skill of $\mathrm{IH}$ recognition was long-lasting, ${ }^{11-15}$ the validity of energy intake reports has been questioned. ${ }^{24}$ Therefore, the rejection of the null hypothesis between scheduled and demanded meals by biophysical, objective measurements completes, validates, and confirms the demonstration that we already obtained from the diaries. We found no significant differences between diary energy intake and total daily expenditure by doubly labeled water at recruitment, in the pre/post longitudinal differences, or after training. Reductions in energy expenditure after training validate all diary decreases in energy intake and mean BG after training. Interruptions of mealtime automatic habitual eating on the first training day, the discovery of $\mathrm{IH}$, and the checking of $\mathrm{IH}$ recognition by BG could maintain energy balances, low mean BG levels, insulin sensitivity, and low triglyceride levels and stop recurrent diarrhea, a mild manifestation of subclinical inflammation in infants (proinflammatory and reversible immune deficiency states are synonymous). ${ }^{25-30}$ IHMP, as a learned skill, may be remembered and used at subsequent ages to reduce fattening, subclinical inflammation, and metabolic risks. ${ }^{7-15,25-30}$

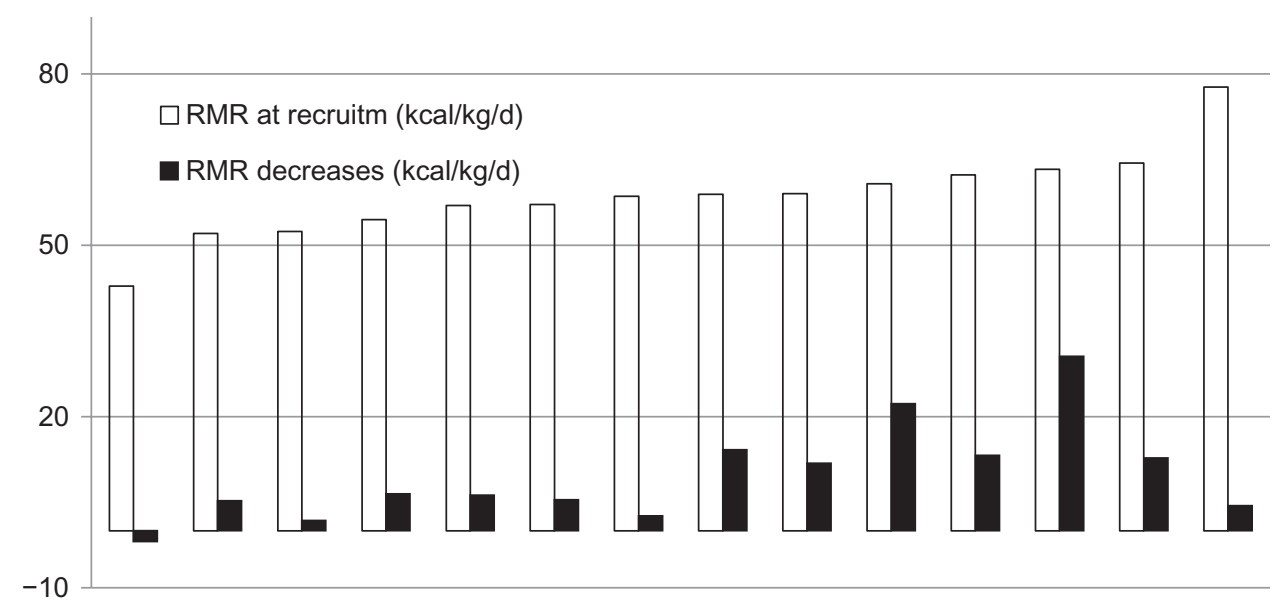

Figure I Resting metabolic rate $(R M R)$ decreases $(P<0.01)$ in seven infants with low RMR at recruitment in comparison with seven infants with high RMR at recruitment $(P<0.0 \mathrm{l})$.

Note: White columns show RMR values and black columns show respective decreases after training in the initial demand meal pattern. 
At recruitment, the seven toddlers above the median RMR had a mean RMR of $63.8 \pm 6.5 \mathrm{kcal} / \mathrm{d}$, which was $17 \%$ greater than the seven toddlers below the median RMR $(\mathrm{RMR}=53.5 \pm 5.3 \mathrm{kcal} / \mathrm{kg} / \mathrm{d})$ (Figure 1). The high-RMR toddlers had a significantly larger RMR pre/post decrease than the low-RMR toddlers ( $P<0.01$ for both differences), indicating a larger shift after training $(49.0 \pm 9.1 \mathrm{kcal} / \mathrm{d})$ in high-RMR toddlers toward the mean RMR of the entire group. We did not observe a similar relationship between the values at recruitment and after training in terms of energy intake and TEE decreases, but we found a similar trend in mean BG in previous investigations on clinically similar toddlers of the same age, as well as in adults. ${ }^{7,11}$ Mean BG was the mean of 21 preprandial BG measurements that adults and mothers performed at home before three daily meals and reported in their feeding diaries. ${ }^{7-11}$ Mean BG characterized habits in the provision of energy to body cells. ${ }^{7-11}$ The associated decreases in both mean BG and RMR substantiate the accuracy in BG estimation by the subjective sensation of weakness, a frequent form of IH reported by older children and adults. ${ }^{7,9}$ Animal experiments confirm that hunger and feeding begin as RMRs decrease. ${ }^{31}$ The respiratory quotient did not show any pre/ post differences $(122.0 \pm 3.8$ and $122.5 \pm 2.5)$.

In the first days of life, scheduled and demanded feeding are equivalent for new mothers and are dictated by familial and medical customs, current local fashions, and convenience, and care-givers can move to scheduled feeding or to demanded feeding. Our results indicate that demanded feeding is an inherent homeostatic mechanism for the maintenance of healthy weight and activity, and that scheduled feeding risks a pattern of chronic pathologies. The vast increase in children with excess body fat, insulin resistance, diabetes, and the consequent immune deficiency (subclinical inflammation) is clearly related to risks and functional impairments in association with high energy intake, high mean BG, high RMR and TEE, and high insulin resistance, and scheduled meal presentation is associated with these negative sequelae..$^{7-15}$ Given the stability of intake habits ${ }^{11-15}$ and the simplicity of choosing demanded feeding versus scheduled feeding, an adjustment in advice to new mothers on healthy meal patterns from the first neonatal days is suggested.

\section{Acknowledgments}

The authors wish to thank Laura Chiesi for the dietary analysis, Massimiliano Sifone for help with the statistical analysis, and Cutberto Garza for helpful suggestions during data collection of data. This research was supported by the Italian Ministry of University, Research, Science and Technology grants for the years 1998-2002 and by ONLUS Nutrizione e Prevenzione, Firenze, for the years 2003-2012.

\section{Disclosure}

The authors report no conflicts of interest in this work.

\section{References}

1. Juonala M, Magnussen CG, Berenson GS, et al. Childhood adiposity, adult adiposity, and cardiovascular risk factors. $N$ Engl $\mathrm{J} \mathrm{Med}$. 2011;365:1876-1885.

2. Weiss R. Insulin sensitivity and secretion: swaying the pendulum. $\mathrm{GH}$, growth hormone, IGF-I, insulin-like growth factor. J Pediatrics. 2006;148:3-4.

3. Verdich C, Toubro S, Buemann B, Madsen JL, Holst JJ, Astrup A. The role of postprandial releases of insulin and incretin hormones in meal induced satiety. Effect of obesity and weight reduction. Intern $J$ Obesity. 2001;25:1206-1214.

4. Singhal A, Cole TJ, Fewtrell M, Lucas A. Breastmilk feeding and lipoprotein profile in adolescents born preterm: follow-up of a prospective randomised study. Lancet. 2004;363:1571-1578.

5. Eriksson JG. Early growth and coronary heart disease and type 2 diabetes: findings from the Helsinki Birth Cohort Study (HBCS). Am J Clin Nutr. 2011;94:1799S-1802S.

6. Waterland RA, Garza C. Potential mechanisms of metabolic imprinting that lead to chronic disease. Am J Clin Nutr. 1999;69:179-197.

7. Ciampolini M. Requested meals versus scheduled meals. Int $J$ Gen Med. 2012;5:345-353.

8. Ciampolini M. Meal by Meal Dynamic Energy Balance in Blood. Kerala, India: Research Signpost; 2011

9. Ciampolini M, Bianchi R. Training to estimate blood glucose and to form associations with initial hunger. Nutr Metab (Lond). 2006; 3:42.

10. Ciampolini M, Lovell-Smith D, Sifone M. Sustained self-regulation of energy intake. Loss of weight in overweight subjects. Maintenance of weight in normal-weight subjects. Nutr Metab (Lond). 2010;7:1-4.

11. Ciampolini M, Sifone M. Differences in maintenance of mean blood glucose (BG) and their association with response to "recognizing hunger." Int J Gen Med. 2011;4:403-412.

12. Ciampolini M, Conti A, Bernardini S, et al. Internal stimuli controlled lower calorie intake: effects after eight months in toddler's diarrhoea. Ital J Gastroenterol. 1987;19:201-204.

13. Ciampolini M, Vicarelli D, Seminara S. Normal energy intake range in children with chronic non-specific diarrhea. Association of relapses with the higher level. J Pediatr Gastroenterol Nutr. 1990;11(3):42-350.

14. Ciampolini M, Bini S, Giommi A, Vicarelli D, Giannellini V. Same growth and different energy intake over four years in children suffering from chronic non-specific diarrhea. Int J Obesity. 1994;18: 17-23.

15. Ciampolini M, Borselli L, Giannellini V. Attention to metabolic hunger and its effects on Helicobacter pylori infection. Physiol Behav. 2000;70:287-296.

16. Jones VA, McLaughlan P, Shorthouse M, Workman E, Hunter JO. Food intolerance: a major factor in the pathogenesis of irritable bowel syndrome. Lancet. 1982;2:1115-1117.

17. McCance RA, Widdowson EM, Southgate DAT. The Composition of Foods, 3rd ed. London: HMSO; 1960.

18. Livesey G. Energy values of unavailable carbohydrate and diets: an inquiry and analysis. Am J Clin Nutr. 1990;51:617-637.

19. Anderson JW, Bridges SR. Dietary fiber content of selected foods. Am J Clin Nutr. 1988;47:440-447.

20. Advisory group meeting on stable isotope reference samples for geochemical and hydrological investigations; IAEA; September 19-21, 1983; Vienna. Gonfiantini R. Report to the Director General; 1984. Available from: http://www-naweb.iaea.org/NAALIHL/docs/pub/ IAEA-1984-Gonfiantini_AGMeeting-StableIsotopeRM.pdf. Accessed. January 17, 2013. 
21. Schoeller DA, Ravussin E, Schutz Y, Acheson KJ, Baertschi P, Jequier E. Energy expenditure by doubly labeled water: validation in humans and proposed calculation. Am J Physiol Regul Integr Comp Physiol. 1986;250:R823-R830.

22. Butte NF, Wong WW, Hopkinson JM, Heinz CJ, Mehta NR, Smith EO. Energy requirements derived from total energy expenditure and energy deposition during the first two years of life. Am J Clin Nutr. 2000;72:1558-1669.

23. Duhigg C. The Power of Habit: Why We Do What We Do in Life and Business. New York: Random House; 2012.

24. Acheson KJ, Campbell IT, Edholm OG, Miller DS, Stock MJ. The measurement of food and energy intake in man - an evaluation of some techniques. Am J Clin Nutr. 1980;33:1147-1154.

25. Festa A, D’Agostino R Jr, Howard G, Mykkänen L, Russell PT, Haffner SM. Chronic subclinical inflammation as part of the insulin resistance syndrome: the Insulin Resistance Atherosclerosis Study (IRAS). Circulation. 2000;102:42-47.
26. Reaven GM. The metabolic syndrome: is this diagnosis necessary? Am J Clin Nutr. 2006;83:1237-1247.

27. Smith CW. Diet and leukocytes. Am J Clin Nutr. 2007;86:1257-1258.

28. Bigorgne AE, Bouchet-Delbos L, Naveau S, et al. Obesity-induced lymphocyte hyperresponsiveness to chemokines: a new mechanism of fatty liver inflammation in obese mice. Gastroenterology. 2008;134:1459-1469.

29. Cani PD, Amar J, Iglesias MA, et al. Metabolic endotoxemia initiates obesity and insulin resistance. Diabetes. 2007;56:1761-1767.

30. Stratton IM, Adler AI, Neil HAW, et al. Association of glycaemia with macrovascular and microvascular complications of type 2 diabetes (UKPDS 35): prospective observational study. $\mathrm{Br} \mathrm{Med} J$ 2000;321:405-412.

31. Nicolaidis S, Even P. Physiological determinant of hunger, satiation and satiety. Am J Clin Nutr. 1985;42:1083-1092.
International Journal of General Medicine

\section{Publish your work in this journal}

The International Journal of General Medicine is an international, peer-reviewed open-access journal that focuses on general and internal medicine, pathogenesis, epidemiology, diagnosis, monitoring and treatment protocols. The journal is characterized by the rapid reporting of reviews, original research and clinical studies across all disease areas.

\section{Dovepress}

A key focus is the elucidation of disease processes and management protocols resulting in improved outcomes for the patient.The manuscript management system is completely online and includes a very quick and fair peer-review system. Visit http://www.dovepress.com/ testimonials.php to read real quotes from published authors.

Submit your manuscript here: http://www.dovepress.com/international-journal-of-general-medicine-journal 